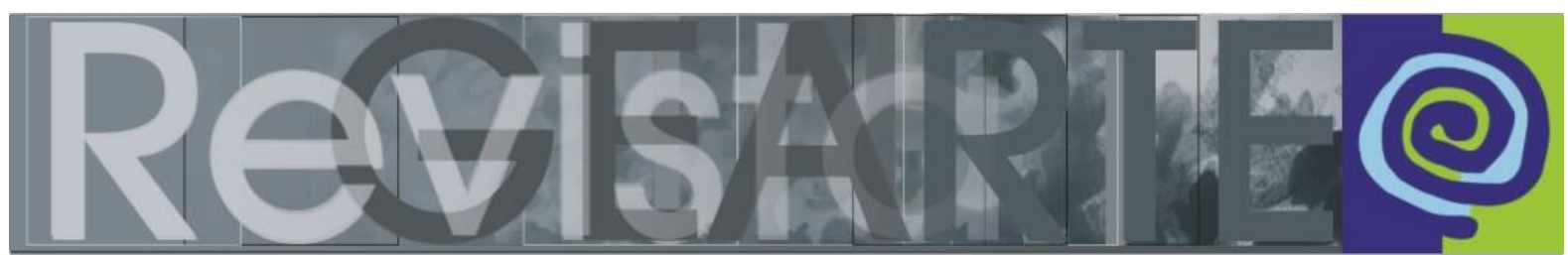

ISSN 2357-9854 | e-ISSN 2596-3198 (online)

\title{
Navegar entre fronteiras: apontamentos sobre o Ensino de Artes Visuais na Universidade Federal da Integração Latino Americana
}

\author{
Gabriela Canale Miola \\ (Instituto Latino-americano de Arte, Cultura e História da Universidade \\ Federal da Integração Latino-americana — UNILA, Foz do Iguaçu/PR, Brasil)
}

RESUMO - Navegar entre fronteiras: apontamentos sobre o Ensino de Artes Visuais na Universidade Federal da Integração Latino Americana - Apontam-se práticas e reflexões do Ensino de Artes Visuais em andamento no contexto bilíngue e interdisciplinar da Universidade Federal da Integração Latino-americana. São assinaladas algumas características da implantação do projeto latino-americanista da universidade em Foz do Iguaçu, fronteira com Argentina e Paraguai. Por fim, apontam-se alguns desafios e práticas de Ensino decolonial das Artes em contexto multicultural.

PALAVRAS-CHAVE

Artes Visuais. Ensino da Arte. UNILA. Decolonial.

RESUMEN - Navegar entre fronteras: apuntes sobre la Enseñanza de Artes Visuales en la Universidad Federal de la Integración Latinoamericana - Se apuntan prácticas y reflexiones de la Enseñanza de Artes Visuales en marcha en el contexto bilingüe e interdisciplinario de la Universidade Federal da Integração Latino-americana. Se señalan algunas características de la implantación del proyecto latinoamericano de la universidad en Foz do Iguaçu, frontera con Argentina y Paraguay. Por último, se plantean algunos desafíos y prácticas de Enseñanza decolonial de las Artes en contexto multicultural.

PALABRAS CLAVE

Artes Visuales. Educación Artística. UNILA. Decolonial. 


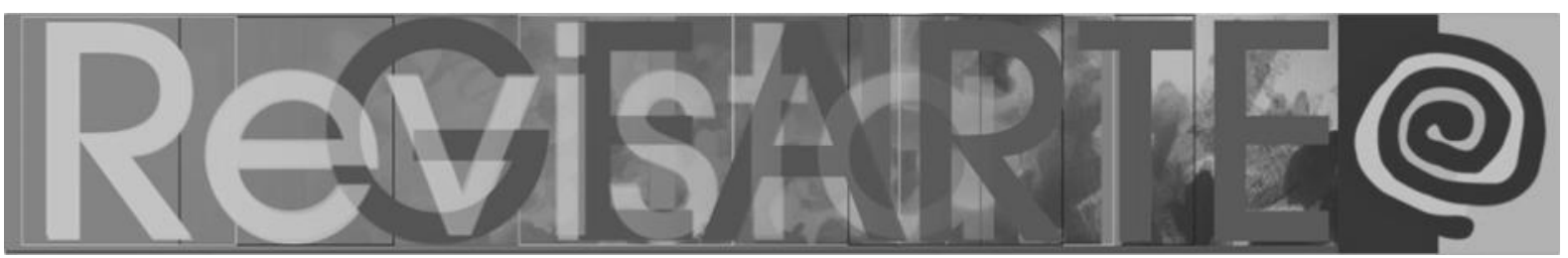

Figura 1 - Laboratório de Artes Visuais da UNILA. Registro da montagem da I Mostra de Arte Contemporânea da Tríplice Fronteira realizada no segundo semestre de 2018 pelos alunos que cursaram as disciplinas Estéticas Contemporâneas e Genealogia das Artes

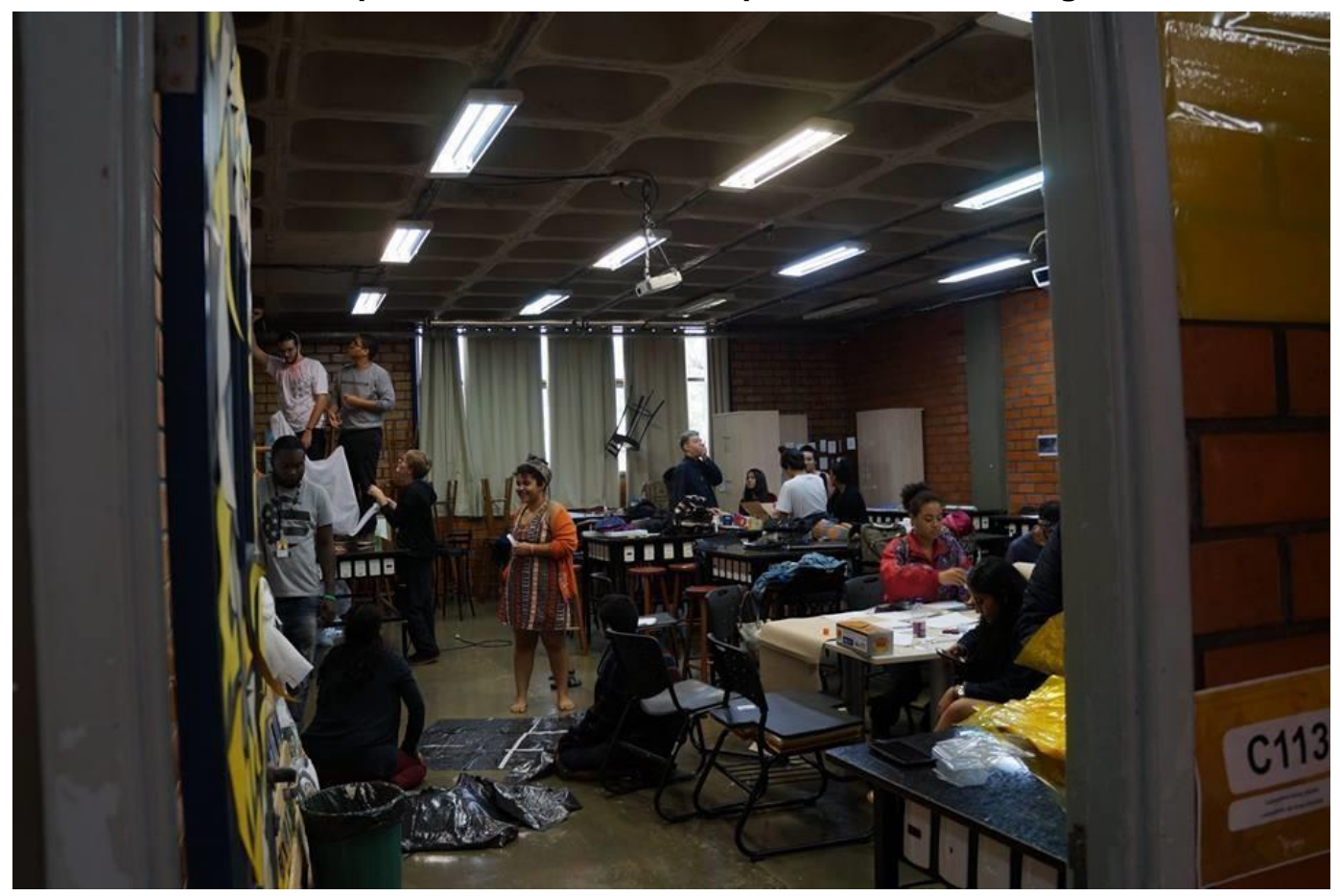

Fonte: Arquivo da autora.

Escrevo desde muitas fronteiras. Desde 2014 sou docente de Artes Visuais na Universidade Federal da Integração Latino Americana (UNILA), localizada em Foz do Iguaçu - fronteira entre Brasil, Paraguai e Argentina. A universidade possui um projeto bilíngue, interdisciplinar e latino-americanista. Recebe estudantes de todas as regiões da América Latina em seus 29 cursos de graduação, 5 especializações, 11 mestrados e um programa de doutoramento. Criada pela Lei no $12.189 / 2010$, no governo Lula, durante a gestão de Fernando Haddad, a UNILA tem como missão "formar recursos humanos aptos a contribuir com a integração latino-americana, com o desenvolvimento regional e com o intercâmbio cultural, científico e educacional da América Latina, especialmente no Mercado Comum do Sul".

Quando cheguei aqui fui movida pelo sonho de um espaço de trocas decoloniais. Vim mobilizada pela leitura da missão da universidade. Depois de quase 5 anos de ensino, extensão e pesquisa olho para a jovem doutora que aqui chegou e só penso em dois conselhos que gostaria de ter me dado: o papel aceita tudo - veja 


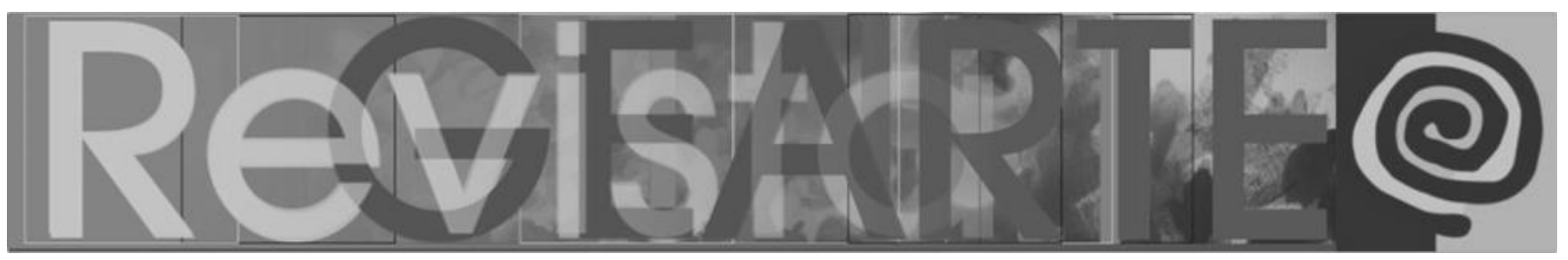

além do projeto e da missão da universidade. E tenha persistência crítica, que o tempo da universidade é mais longo que a ansiedade da juventude.

Escrevo em primeira pessoa com uma certa culpa. Gostaria de forjar um distanciamento científico. Talvez mais tarde o faça. Por ora preciso assumir o que trago para a sala de aula e o que abandono. Assinalar isso é, também, um gesto político e decolonial.

Atuo principalmente em um curso que se chama Letras - Artes e Mediação Cultural (LAMC) que foi criado inicialmente como uma estratégia de pensar como seria um curso de Letras no século XXI. Atualmente o curso se encaminha para pensar a Mediação Cultural como estratégia de interlocução crítica e ativa com o mundo, desde perspectivas decolonias. O curso de LAMC é bastante jovem e o único no país. Ele é focado nas Letras, Artes e Comunicação e possui intersecções com a História, a Antropologia, o audiovisual, a Sociologia e as Humanidades em Geral. O desafio é grande.

Nos dois primeiros anos os estudantes cursam, assim como todos os graduandos da universidade, o que chamamos de Ciclo Comum. São três disciplinas de 4 créditos sequenciais denominadas Fundamentos da América Latina (FAL) que introduzem temas diversos - da colonização do século XV à televisão no século XXI. A proposta é falar desse espaço geográfico desde uma perspectiva decolonial. Portanto não se trata apenas de mudar o foco do espaço analisado, mas a epistemologia com que se compreende esse lugar diverso e uno. Além da FAL, todos os estudantes da universidade cursam uma segunda língua. Os brasileiros (que são maioria) cursam Espanhol e os hispanohablantes cursam Português. Na vida cotidiana nossa língua é o Portunhol.

Em Letras - Artes e Mediação Cultural há ainda as disciplinas obrigatórias chamadas Terceira Margem em que se estuda Guarani. São ofertadas ocasionalmente também Quechua. Aqui já começam as questões que me faço sobre a possibilidade de uma universidade decolonial de fato. Além do Português, do 


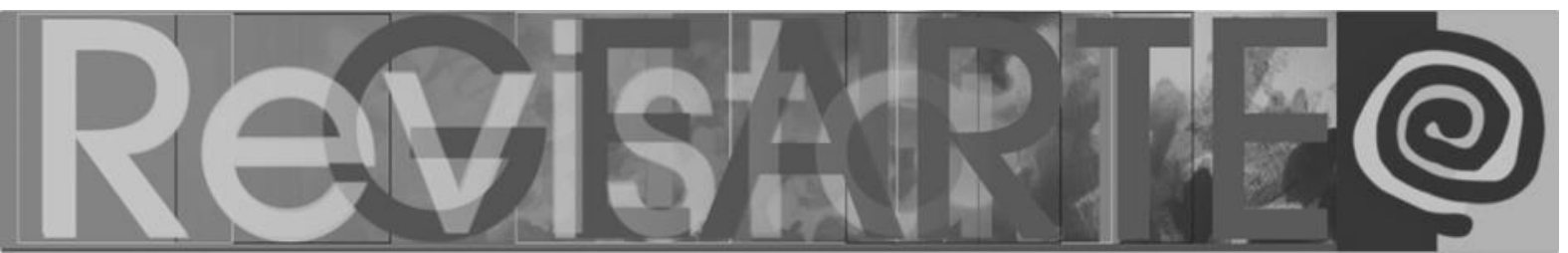

Espanhol e do Guarani centenas de outras línguas de ficam de foram, como Francês, Créole - línguas maternas dos nossos alunos haitianos e centenas de línguas dos povos originários. Muitos cursos têm se posicionado para reduzir a carga horária do Ciclo Comum. Há diferentes percepções da importância dessa formação nos Institutos e graduações.

Em sala de aula tenho estudantes de quase toda América Latina. Ministro as disciplinas Genealogia das Artes, Direção de Arte, Culturas Digitais, Estéticas Contemporâneas, Fundamentos da América Latina; Arte, recepção e Comunidade. Minha grande questão tem sido como ensinar de forma decolonial para grupos com repertorio tão distinto. Uso a palavra repertório não apenas para descrever o conjunto de obras de artes a que elas e eles tiveram acesso, mas às experiências subjetivas, à ideia de ensino, aos campos de interesse, aos valores, às relações que estabelecem com as tensões vividas no nosso continente.

Há certamente um contexto que nos une. A história de colonização, os rastros do genocídio de grupos indígenas e dos povos africanos sequestrados e trazidos para cá. Há a concentração de poder nas suas mais variadas escalas - do poder midiático ao poder da política institucional - comuns a toda América Latina. Darcy Ribeiro, Walter Mignolo, Nestor Garcia Canclini, Boaventura de Souza Santos me ajudam a entender esse contexto. Vejam como meu repertório é acadêmico, canônico e bastante masculino. Vejam o meu próprio desafio de me desconstruir.

Aí entro em outra questão, igualmente desafiadora. Como produzir saber e reflexão a partir da estrutura cristalizada do ensino na universidade em que tudo é separado por disciplina (mesmo que ela se pretenda interdisciplinar), tem carga horária fixa, sala de aula padronizada, nota, chamada. Além da escala hierárquica de cargos e títulos. É complexo perceber como um professor doutor se relaciona com saberes que na sua formação possivelmente foram desqualificados por serem de uma classe social ou contexto segregados. 


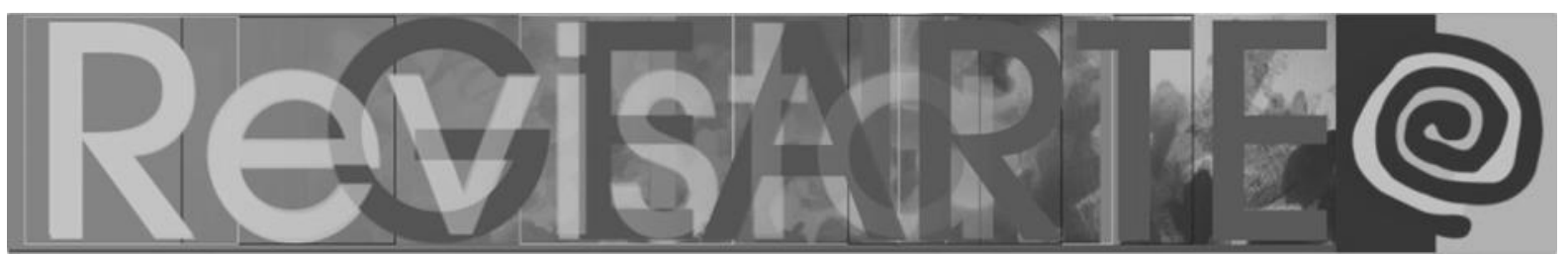

Na minha prática observo que os estudantes têm uma percepção estrita do que venha a ser ensino. O modelo de cátedra seguido de prova está introjetado. Aquilo que se distancia disso é alvo de desqualificação pela maioria. Sobre isso não tenho dados além da minha percepção e experiência. O que se passou comigo foi um processo interno de negociação entre experiências de ensino que considero decoloniais e o formato convencional que os estudantes reconhecem como aula. Aí está mais um dado do contato de um projeto decolonial com a "realidade".

Nesse sentido da tensão entre projeto e a concretização dele, a imagem mais emblemática é a construção do corpo físico da universidade. Hoje ela funciona em várias partes da cidade de Foz do Iguaçu. Os principais em que há aula são dois. Dentro da hidrelétrica Itaipu Binacional, onde foi criada. É no mínimo intrigante estar em um espaço de segurança nacional e em uma universidade ao mesmo tempo. Para entrar nesse espaço é preciso de autorização, uma carteirinha e passar por uma barreira de controle. Daí a dificuldade do acesso da população a muitos eventos e à biblioteca.

O segundo principal local de aulas fica no Jardim Universitário, localizado na Vila $\mathrm{C}$, onde atuo. Esse bairro nasceu como região de moradia para os trabalhadores da implantação de Itaipu. As casas foram separadas por categoria laboral. Os engenheiros e diretores viviam na Vila $B$ - onde há um clube, grandes casas sem cerca no melhor estilo american way of life dos subúrbios estadunidenses; a Vila A, em que viviam os técnicos em casa de alvenaria com cerca e um pequeno pátio e a Vila $\mathrm{C}$ em que viviam os trabalhadores braçais que dividiam pequenas casas de telhado de zinco em uma região em que faz mais de 40 graus boa parte do ano.

O campus do Jardim Universitário da Vila C é um antigo prédio da Uniamérica, universidade particular que "alugou" o espaço em troca de redução de sua dívida com o Estado.

Para a universidade foi projetado um complexo arquitetônico assinado por Oscar Niemayer. A obra começou a ser construída em um terreno doado por Itaipu. 


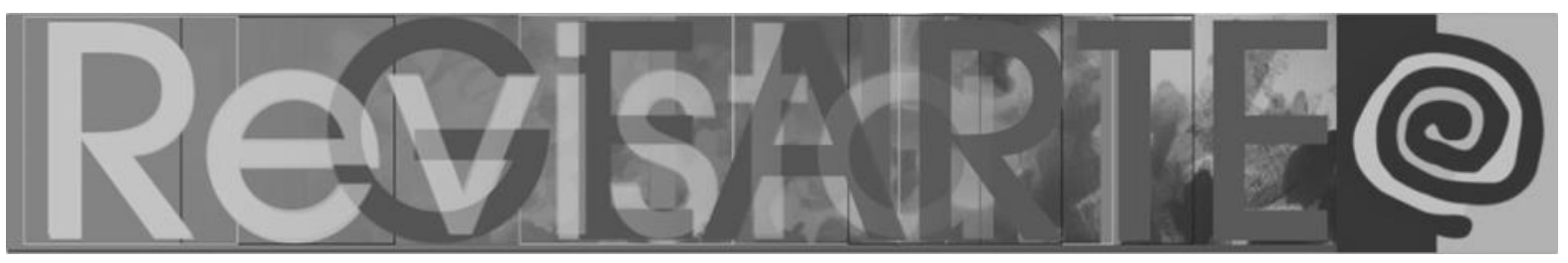

Há anos ela está parada por questões judiciais. O início de seu esqueleto segue na paisagem e no orçamento.

Um grande desafio tem sido a relação da universidade com a comunidade. Os mais de 100 projetos de extensão dão conta de abranger boa parte da cidade, atuando nas mais diversas áreas. Quando cheguei aqui a percepção da universidade por parte dos moradores locais era bastante problemática e segue sendo, talvez em menor escala. Era e é comum associar os estudantes ao uso de drogas ilícitas e à desordem. Era muito usual até 2014 ver a polícia acompanhada da TV local atuando em festas de estudantes. A veiculação de notícias denegrindo a imagem dos estudantes que deixaram suas casas para estudar aqui foi intensa e concentrada. ${ }^{1}$

A maior parte do ensino privado local pertence a um grupo da cidade que detém desde o ensino pré-escolar à pós-graduação, além de influenciar boa parte dos meios de comunicação. A maior incidência de evasão entre os estudantes da universidade é de pessoas da própria cidade. A justificativa para esse dado é complexa, mas creio que passa também por essa construção do imaginário local sobre a universidade.

Aí entramos em outro ponto. Há o sonho decolonial e há a implementação dele. A UNILA foi criada no REUNI, projeto de expansão e descentralização do ensino superior. As universidades se multiplicaram, o número de técnicos, docentes e discentes ascendeu. A implementação de muitas delas segue em curso. Muitos cursos foram implementados sem o corpo de profissionais e estrutura mínimos. Nos últimos anos essas demandas conseguiram ser atendidas em boa parte, o número de técnicos e docentes é grande.

1 A notícia de 11 de junho de 2012 resume a perseguição sofrida pelos estudantes. Na linha fina da matéria lê-se "Estudantes da Universidade Federal da Integração Latino-Americana (Unila) denunciaram nesta segunda-feira (11) que um grupo de policiais militares (PM) invadiu, durante a madrugada de hoje, a Moradia 1 dos estudantes sob o pretexto de atender a uma reclamação de vizinhos por "perturbação do sossego". No entanto, não há vizinhos no entorno da moradia e, segundo a própria PM, não houve a constatação de "perturbação do sossego". (link nas referências). 


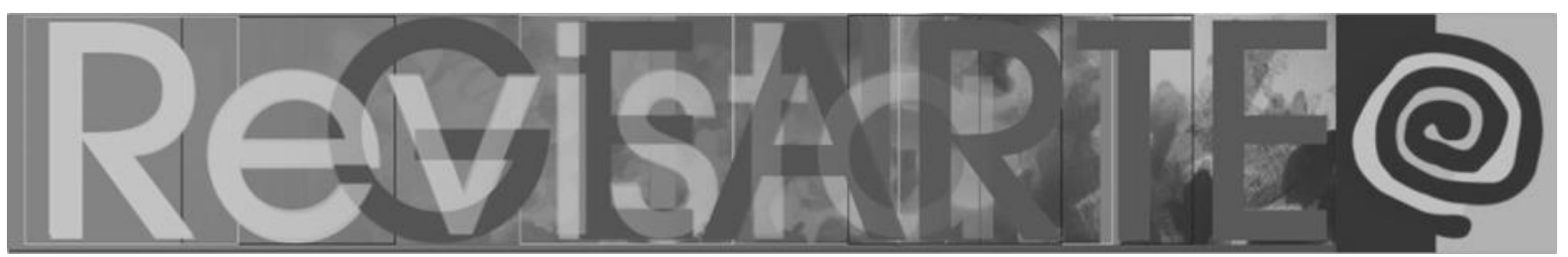

Além disso, no caso da UNILA e da UNILAB, havia a previsão de orçamento específico para sua implementação plena. No governo de Michel Temer foi aprovada a chamada "PEC do fim do mundo" na qual o investimento em educação foi congelado por 20 anos. Isto é, as universidades como a UNILA tiveram sua implementação comprometida.

Esses parágrafos anteriores dão conta de uma pequena parcela do que tem sido o ensino das artes nessa universidade. São percepções, observações, descrições contextuais. São desafios que fervilham no caldeirão do que tem sido ensinar aqui.

Desde o início me oriento pela Abordagem Triangular da querida Ana Mae Barbosa. Elas (a Abordagem e Ana) me foram absolutamente iluminadoras quando ensinei Artes Visuais no projeto piloto da Casa de Cultura e Cidadania na fronteira entre São Paulo e Diadema com curadoria pedagógica da Heloísa Margarido e Ana Mae Barbosa. Atuava em uma comunidade de altíssima vulnerabilidade com índices de violência e analfabetismo alarmantes. Duas ideias me foram centrais naquela época. A primeira seria buscar manter a base do fazer arte, ver arte e entender arte - que foi a forma mais simplificada possível da proposta triangular que pude encontrar. Foi complexo, sobretudo para articular o que eu entendia como arte. Tive que me reinventar. Hoje, dentro da UNILA, olho para essa experiência e reconheço o quanto de colonialista havia arraigado em mim. Eu, doutoranda, branca, morando nos Jardins, querendo ensinar arte na Vila Guacuri. Busquei muita inspiração no grafite, na pichação e na cultura midiática - que eu tentei misturar com artistas e procedimentos artísticos que pudessem fazer algum sentido para os educandos que tinham de 5 a 17 anos e ficavam conosco no contra turno da escola.

O espaço foi construído em um antigo circo-escola. Trabalhávamos por área, com horários fixos na grade dos estudantes que podiam escolher o que thes interessava. O projeto era patrocinado pela AES Eletropaulo - braço brasileiro da megacorporação estadunidense de produção e distribuição de energia elétrica. A casa 


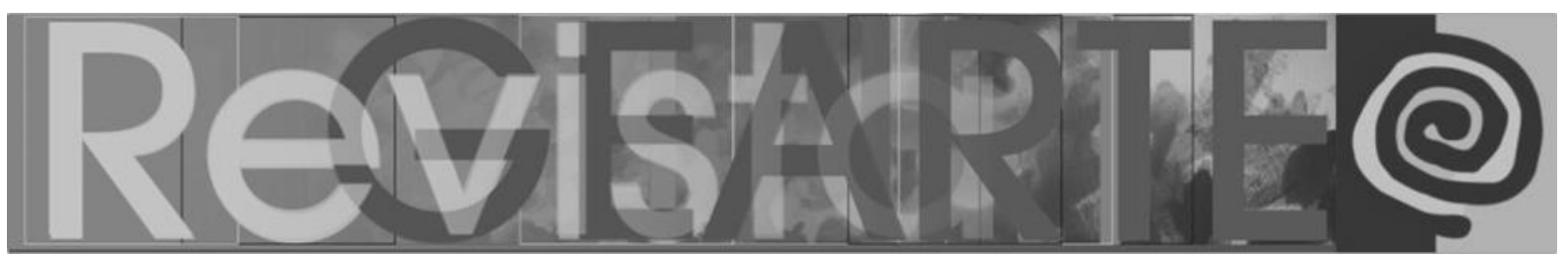

de Cultura e Cidadania aos poucos se distanciou das propostas desenvolvidas por seus curadores e abrigou cada vez mais a lógica de receber eventos também patrocinados pela empresa e reafirmar a necessidade daquela população de trocar os gatos de energia elétrica pela rede oficial.

Tinha a Abordagem Triangular como uma espécie de mapa maleável. Também me guiei por uma fala da Ana nas orientações mensais. Ana disse para sempre focarmos no sonho daqueles meninos e meninas. Hoje, na UNILA, começo a trabalhar com uma proposta que se chama Projeto Vital. É uma experiência que está em desenvolvimento na UNAE, Universidad Nacional de Educación, do Equador. A ideia é estimular o pensamento investigativo (que se pergunta o que investigar, como investigar e por que investigar), assumindo práticas e posturas claras e consequentes. Nesse sentido, a educação é pensava e vivida implicando conhecimentos, habilidades, emoções, atitudes e valores para potencializar a interculturalidade. Os objetivos principais desses processos seriam a intepretação, a tomada de decisão e a atuação futura e atual dos estudantes em seus contextos. Aí está mais um grande desafio porque muitos nossos estudantes retornam para seus países de origem e atuam e suas regiões. Tão freireano!

Para exemplificar essas práticas conto um pouco das experiências que tenho tido na disciplina Genealogia das Artes. No início do curso de Letras - Artes e Mediação Cultural, ela se chamava Genealogia das Artes no Ocidente. Com o tempo se entendeu que o conceito de Ocidente, via de regra, exclui um universo enorme de produções culturais latino-americanas já que a matriz do que se tem chamado Ocidente se pauta em visões orientadas ao desenvolvimento e a uma ideia civilização caduca e eurocêntrica.

Tenho tentado me afastar da visão da arte como um grande processo linear e evolutivo em que alguns artistas são vistos como gênios. Além disso, incluo na proposta triangular da Ana Mae um outro eixo - perceber a circulação da obra - tanto no momento em que analisamos aquelas existentes como quando criamos as nossas. 


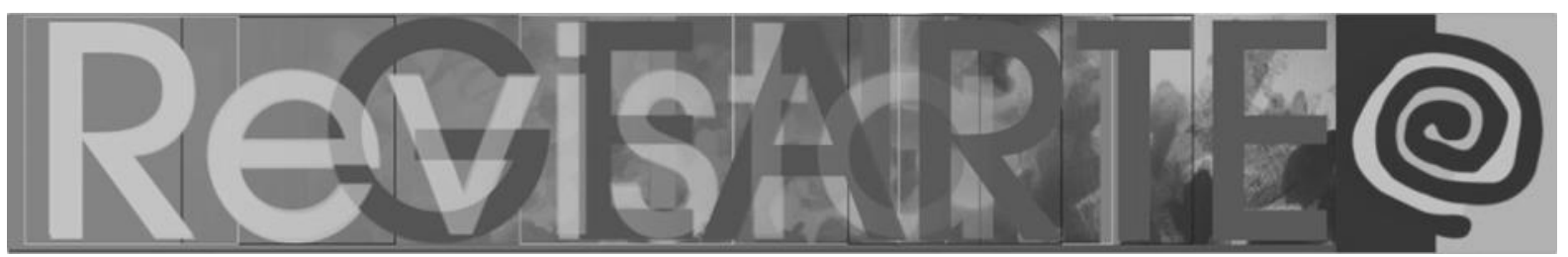

Essa camada possibilita aprofundar os contextos em que a obra foi criada e de que forma ela é vista ao longo do tempo. Além disso, durante as atividades de criação, ao pensar na circulação do que criam, os estudantes pensam nos mecanismos de circulação da imagem e do imaginário contemporâneos.

Dentro dessa proposta penso o artista como parte de um contexto, para além da ideia romântica de ser especial e intocável. Busco expandir a ideia de arte que dissocia o que se tem distinguido do artesanato já que, muitas vezes, se trata de uma cisão classista ou hierárquica que desqualifica práticas de grupos que não se enquadram no padrão de "civilidade", de belo, de bem-acabado.

Nos últimos anos tenho buscado incluir exemplos de criações dos povos originários e de artistas que problematizam as questões africanas e afro-brasileiras, muito orientada pelas leis $10.639 / 03$ e 11.645/08, que regulamentam a obrigatoriedade do ensino da História e da Cultura desses grandes e diversos grupos (MIOLA; CORREA, 2017).

Mais do que isso, tenho buscado pensar a ideia de Genealogia das Artes como algo vivo, em que cada estudante pode e deve elaborar sua própria genealogia inclusive fazendo parte do campo da criação. Nesse sentido penso que a criação, como base do triangulo proposto pela Ana, é um gesto político que faz com que o estudante se perceba como autor no mundo da arte. Ele convive de forma crítica e criativa com toda a historiografia da arte, inscrevendo seu trabalho entre as produções que conhece. Dessa forma a Genealogia passa por perceber-se como parte viva dessa construção.

Quando digo viva, penso na criação que eles produzem também como pesquisa. Isto é, entendo que ao criar eles e elas estão articulando de forma investigativa todo o repertório a quem tiveram acesso. A prática artística é também nesse, e em todos os casos, pesquisa. A proposta que desenvolvi em 2018 com uma turma de LAMC e uma turma de Cinema e Audiovisual se organizou da seguinte forma: 


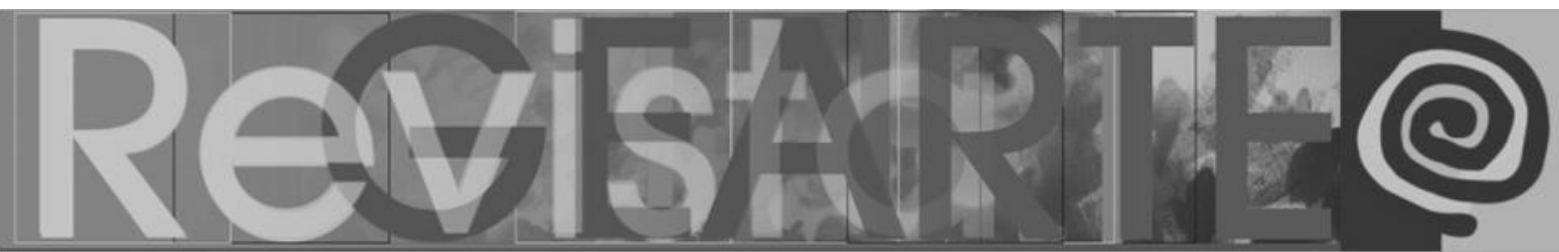

1) Pensamos nos artistas e obras que mobilizaram cada estudante a fim de que cada uma e cada um percebesse sua experiência com a arte de forma crítica. A ideia básica era dialogar com a proposta freireana de partir da experiência de cada um. Ao invés de apresentar os artistas-gênios preferi ouvir que obras e artistas ressoavam nos afetos de cada uma, de cada um. Dialogamos também sobre os processos de ensino a que tiveram acesso durante sua vida e escolar, apontando as premissas conceituais, políticas e sociais que sustentam discursivamente essas práticas.

2) Em seguida debatemos, vimos e analisamos obras, artistas e contextos agrupados por temas que me parecem caros para pensar a arte. Passamos pelas relações entre Arte e Natureza; pelo sagrado na Arte; pela construção da identidade por meio do retrato e da colagem; pela voz, performance e discurso a partir do slam, entre outros.

3) Propus que cada estudante elegesse uma das obras trabalhadas e, para ela, criasse uma resposta artística. A ideia que sustenta essa proposta é a de que a Genealogia das Artes é algo vivo, em movimento, e que cada um pode contribuir e elaborar sua própria genealogia. Também está nessa proposta a premissa de que cada obra de arte revisita todas as outras, instaurando sincronicamente um campo novo, diacronicamente. Eles puderam ter contato direto com os artistas selecionados via WhatsApp, Facebook e e-mail, além de poder ter acesso às obras originais que me foram disponibilizadas pelos artistas Daiane Prado, Giuliano Lucas, Luis Felipe Porto, Gaby Nunes.

4) Por fim montamos uma exposição com os trabalhos desenvolvidos. Nessa fase percebi que a experiência expositiva mais convencional não fazia sentido para muitos estudantes. Não faz parte do cotidiano da maioria a ida a museus e galerias. Portanto essa última fase, que para mim seria uma espécie de síntese do processo, não ressoou para a maioria. Senti-me solitária e colonialista nesse momento. Creio que propus a eles um modelo de compartilhamento de criação artística que é muito mais fundado no meu repertório do que no deles. 


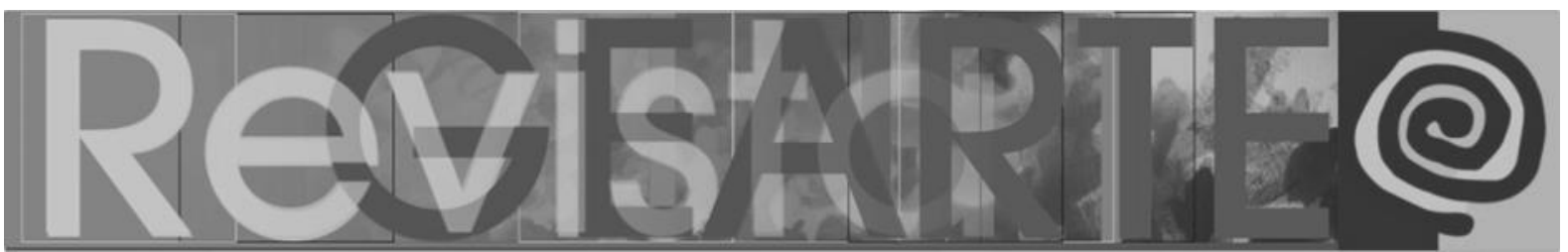

Os desafios são muitos. As fronteiras são infinitas. Esse ano receberemos estudantes com visto humanitário, refugiados e o primeiro grupo de indígenas aldeados. Tudo é processo, travessia.

Figuras 2 a 5 - Registro da montagem da I Mostra de Arte Contemporânea da Tríplice Fronteira realizada no segundo semestre de 2018 pelos alunos que cursaram as disciplinas Estéticas Contemporâneas e Genealogia das Artes
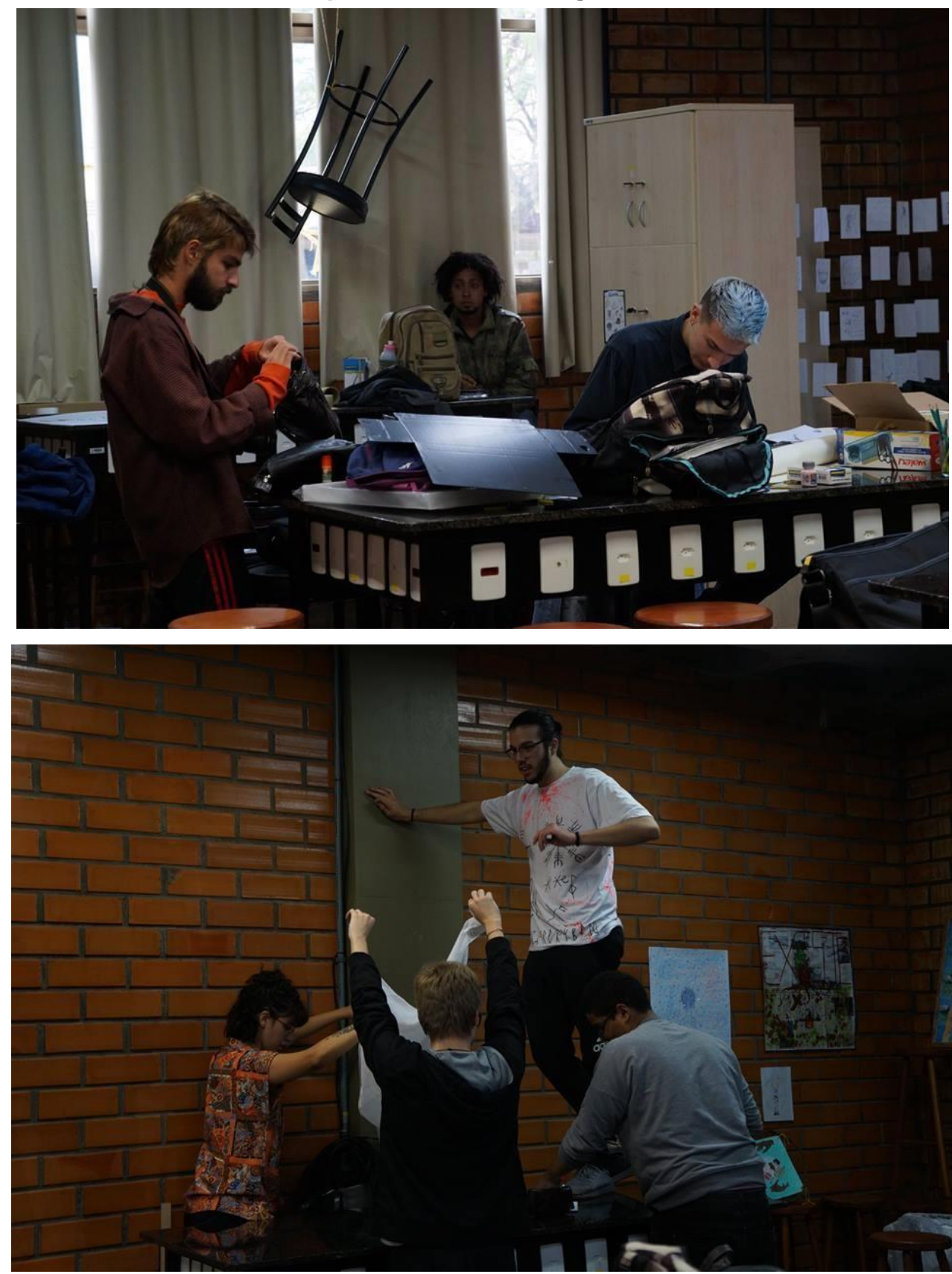

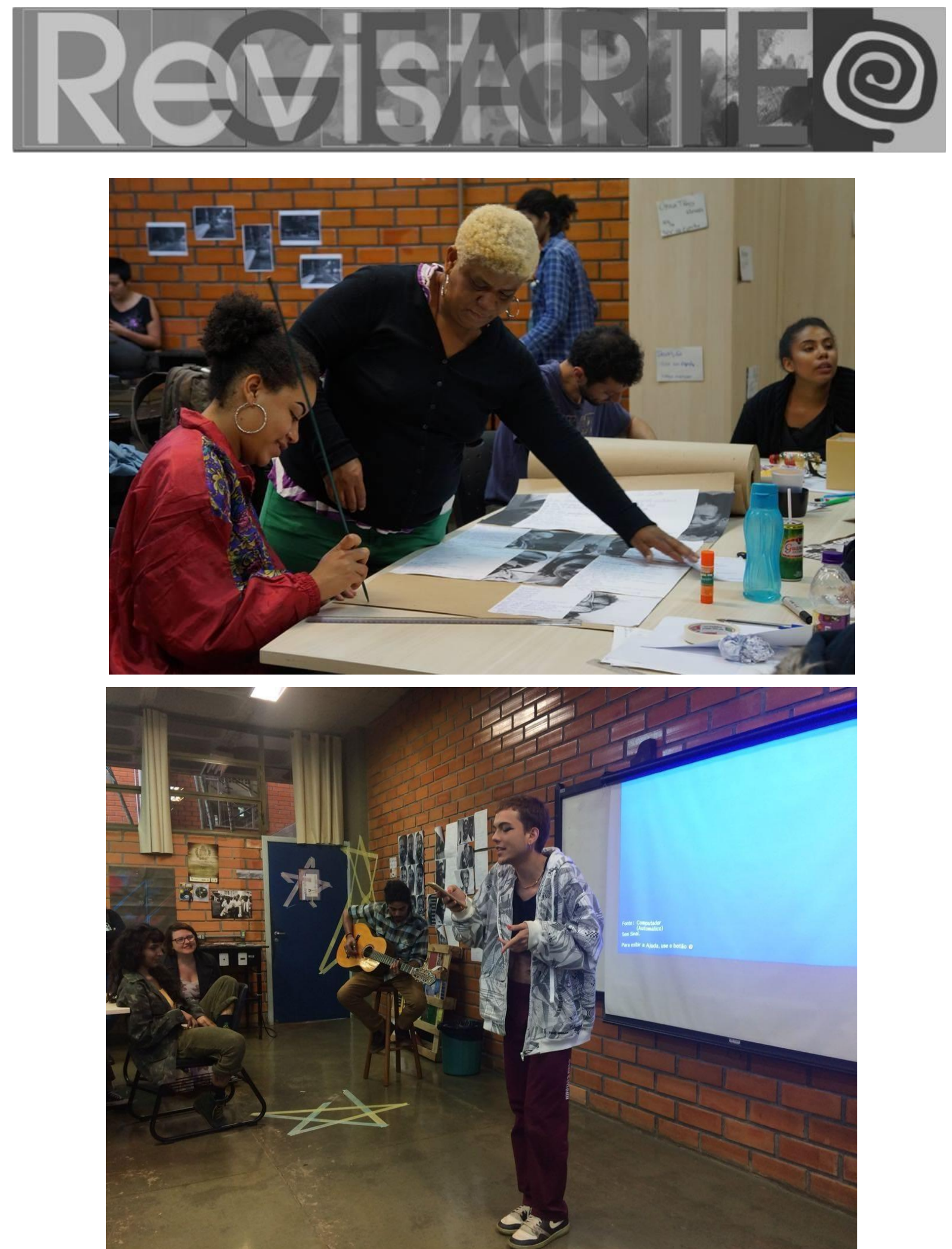

Fonte: Arquivo da autora.

\section{Referências}

BARBOSA, Ana Mae. A imagem no ensino da arte. São Paulo: Perspectiva, 1991.

BARBOSA, Ana Mae. Tópicos Utópicos. Belo Horizonte: C/Arte, 1998a.

BARBOSA, Ana Mae. (Org.). A compreensão e o prazer da arte. São Paulo: SESC Vila Mariana, 1998b.

MIOLA, Gabriela Canale. Navegar entre fronteiras: apontamentos sobre o Ensino de Artes Visuais na Universidade Federal da Integração Latino Americana.

Revista GEARTE, Porto Alegre, v. 6, n. 2, p. 468-481, maio/ago. 2019.

Disponível em: http://seer.ufrgs.br/gearte 


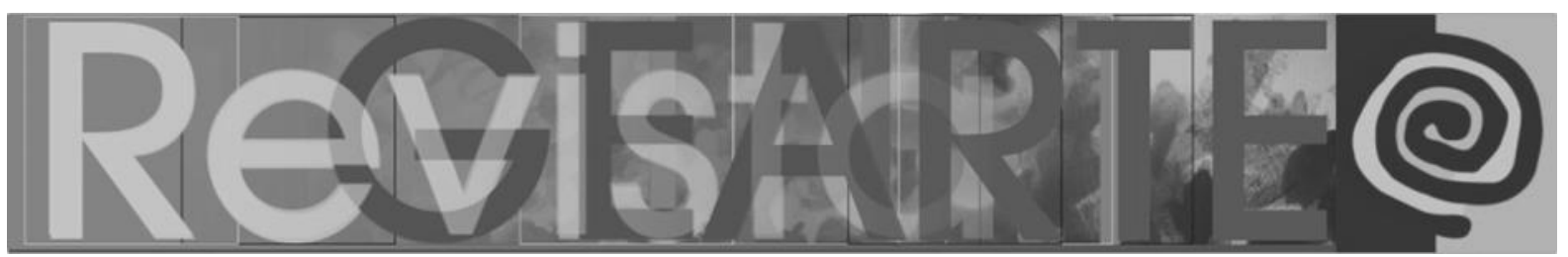

BARBOSA, Ana Mae. Arte-Educação no Brasil. São Paulo: Perspectiva, 2002.

BARBOSA, Ana Mae. (Org.). Arte/Educação contemporânea: consonâncias internacionais. São Paulo: Cortez, 2005.

BARBOSA, Ana Mae. Ensino da arte: memória e história. São Paulo: Perspectiva, 2011.

BARBOSA, Ana Amália Tavares Bastos. Além do corpo: uma experiência em arte-educação. São Paulo: Cortez, 2014.

BRASIL. Lei ํㅜ 12.189, de 12 de janeiro de 2010 Dispõe sobre a criação da Universidade Federal da Integração Latino-Americana - UNILA e dá outras providências. Disponível em: http://www.planalto.gov.br/ccivil_03/_Ato2007-2010/2010/Lei/L12189.htm . Acesso em: 22 fev. 2018.

CANCLINI, Néstor García. Culturas híbridas: estratégias para entrar e sair da modernidade. Tradução de Ana Regina Lessa e Heloísa Pezza Cintrão. São Paulo: Edusp, 2006.

Estudantes da Unila denunciam nova ação da PM. Matéria disponível em

<http://www.vermelho.org.br/noticia/185522-1> Acesso em: 24 fev. 2018.

FANON, Frantz. Pele negra, máscaras brancas. Salvador: EDUFBA, 2008.

FANON, Frantz. Os Condenados da terra. Rio de Janeiro: Civilização Brasileira, 1979.

GÓES, Virginia Santiago dos Santos. Colonialidade do saber e a dinâmica universitária lationoamericana: reflexões desde e com o Eixo de Fundamentos da América Latina da UNILA. 2018. 180 f. Dissertação (Mestrado em Integração Latino-americana) - Universidade Federal da Integração Latino-americana - UNILA, Programa de Pós-Graduação em Integração Contemporânea da América Latina - PPGICAL, Foz do Iguaçu, PR, 2018.

MIGNOLO, Walter. Postoccidentalismo: el argumento desde América Latina. In: CASTRO-GÓMEZ, Santiago; MENDIETA, Eduardo (Coords.). Teorías sin disciplina: latinoamericanismo, poscolonialidad y globalización en debate. México: Miguel Ángel Porrúa, 1998.

MIGNOLO, Walter. Histórias locais/projetos globais: colonialidade, saberes subalternos e pensamento liminar. Trad. Solange Ribeiro de Oliveira. Belo Horizonte: UFMG, 2003.

MIGNOLO, Walter. Os esplendores e as misérias da "ciência ": colonialidade, geopolítica do conhecimento e pluri-versalidade epistêmica. In: SANTOS, Boaventura de Sousa (Org.). Conhecimento prudente para uma vida decente: um discurso sobre as ciências revisitado. São Paulo: Cortez, 2004. p. 667-710.

MIGNOLO, Walter. Histórias locais/ Projetos globais. Colonialidade, saberes subalternos e pensamento liminar. Belo Horizonte: UFMG, 2003.

MIOLA, Gabriela Canale (Org.). Catálogo I Mostra de Letras Artes e mediação Cultural, 2015. Disponível em: <https://issuu.com/gabrielacanale/docs/catalogo_revisado> Acesso em: 24 fev. 2019.

MIOLA, Gabriela Canale; CORREA, Lucas Juliano. Políticas e Poéticas Afirmativas: criação e ensino de Arte na Chave da Cultura Afro-brasileira. ANPAP, 2017. In: PARAGUAI, Luisa Angélica et al (Orgs.). Encontro da Associação Nacional de Pesquisadores em Artes Plásticas: Memórias e Inventações, 26., 2017, Campinas. Anais... Campinas: ANPAP, PUC, 2017. Disponível em: <http://anpap.org.br/anais/2017/PDF/EAV/26encontro__CORREA_Lucas_Juliano_Pereira_MIO LA_Gabriela_Canale.pdf> Acesso em: 12 jun. 2018.

PROJETO PEDAGÓGICO DA UNILA. Disponível em: <https://portal.unila.edu.br/institucional/projetopedagogico> Acesso em: 12 jun. 2018.

QUIJANO, Aníbal. Colonialidad del poder, cultura y conocimiento en América Latina (Análisis). Ecuador Debate. Descentralización: entre lo global y lo local. Quito: CAAP, n. 44, p. 227- 238, ago. 1998. 


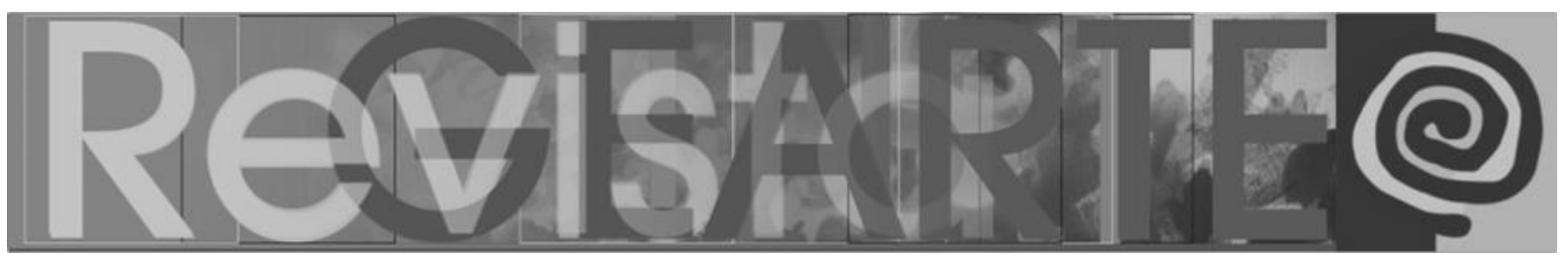

QUIJANO, Aníbal. Colonialidad del poder, globalización y democracia: tendencias básicas de nuestra época. Caracas: Instituto de Altos Estudios Internacionales Pedro Gual, 2000.

QUIJANO, Aníbal. Colonialidade do poder, eurocentrismo e América Latina. In: LANDER, Edgardo (Org.). A colonialidade do saber: eurocentrismo e ciências sociais. Perspectivas latinoamericanas. Colección Sur Sur. Buenos Aires: CLACSO, 2005. p. 107-130.

RIBEIRO, Darcy. As Américas e a civilização: processo de formação e causas do desenvolvimento desigual dos povos americanos. São Paulo: Cia das Letras, 2007.

RIBEIRO, Darcy. A América Latina Existe? Brasília: Editora UNB, 2010.

SANTOS, Boaventura de Sousa. Una epistemología del sur. México: CLACSO y Siglo XXI, 2009.

SANTOS, Boaventura de Sousa. Descolonizar el saber, reinventar el poder. Montevideo: Trilce, 2010.

SANTOS, Boaventura de Sousa. Para além do Pensamento Abissal: das linhas globais a uma ecologia de saberes. Revista Crítica de Ciências Sociais [on-line], v. 78, p. 3-46, out., 2007. Disponível em: <http://rccs.revues.org/753> Acesso em: 25 abr. 2017.

UNILA: Letras - Artes e Mediação Cultural | UNILA. Disponível em: <https://www.youtube.com/watch?v =iSouK_b04hQ> Acesso em: 22 fev. 2018.

VASCONCELOS, José. Ulises Criollo, prólogo de Emmanuel Carballo. México: Trillas, 1998. Vídeo mostra agressão de policiais a estudantes da Unila. Disponível em:

$<$ https://ultimosegundo.ig.com.br/educacao/2012-06-10/video-mostra-agressao-de-policiais-a-estudantesda-unila.html> Acesso em: 24 fev. 2018.

WALSH, Catherine. Pedagogías decoloniales caminando y preguntando: notas a Paulo Freire desde Abya Yala. Revista Entramados - Educación Y Sociedad, v. 1, n. 1, p. 17- 31, 2014.

\section{Gabriela Canale Miola}

É professora do Instituto Latino-americano de Arte, Cultura e História da Universidade Federal da Integração Latino-americana (UNILA). Doutora em Teoria Literária e Literatura Comparada pela Universidade de São Paulo (USP), mestre em Estudos Literários (UEL) e graduada em Comunicação Social (UEL). Como artista pesquisa as múltiplas relações entre as artes - tendo trabalhos expostos no Festival Internacional de Linguagem Eletrônica, Mostra Internacional de Videodança, Bienal de Dança entre outros. Atua como artista-educadora no Coletivo SIM!, vencedor do prêmio de Arte-Educação do Itaú Cultural. Fundadora e coordenadora do projeto Multigraphias de residências artísticas que recebeu mais de 100 artistas, de 10 diferentes países em residências virtuais e presenciais que resultaram em um acervo com milhares de obras e três exposições. Fundadora do "Coletivo SIM!" de Arte e Educação que desenvolve projetos de pesquisa e criação no campo das artes contemporâneas, atuando na confluência entre Artes Visuais, Literatura, Música e Dança. O projeto foi vencedor dos editais Vai e Rumos do Itaú Cultural. Membro dos grupos de Pesquisa "NATLA - Núcleo de Arte e Tecnologia latinoamericano" e "Cartografias Imaginárias: Geopoética da Tríplice Fronteira".

E-mail: gabriela.miola@unila.edu.br

Currículo: http://lattes.cnpq.br/7139310622652380

Recebido em 28 de fevereiro de 2019 Aceito em 25 de maio de 2019 